\title{
Structural elucidation of condensed tannin from the bark waste of Acacia crassicarpa plantation wood in Indonesia
}

\author{
Maya Ismayati ${ }^{1,2} \cdot$ Akiko Nakagawa-izumi $^{1} \cdot$ Hiroshi Ohi $^{1}$
}

Received: 16 November 2016/ Accepted: 9 April 2017/Published online: 9 June 2017

(C) The Japan Wood Research Society 2017

\begin{abstract}
Recently, Acacia crassicarpa has been planted in peatland areas with acidic soil in Indonesia for use in pulp and paper materials. Its bark is not suitable to produce bleached pulp; hence, it is discarded as waste. Meanwhile, in South Africa and other countries, Acacia mearnsii has been planted for a long time, and its bark extracts have been used as a leather tanning agent. First, the structure of condensed tannin from the bark waste of A. crassicarpa is characterized. The yield of the extracts obtained from $A$. crassicarpa using a $70 \%$ acetone aqueous solution $(7 \%$ based on bark weight) is less than that obtained from $A$. mearnsii (34\%). A novel flavan dimer from the condensed tannin, specific to A. crassicarpa, is isolated from the bark extracts. To the best of our knowledge, this dimer is a new compound as evidenced from pyrolysis-gas chromatography-mass spectrometry and nuclear magnetic resonance analyses; it corresponds to a gallocatechin-catechin flavan dimer with the absence of one oxygen atom at the $3 \mathrm{C}$ of the pyran ring. In addition, 2,4,6-trimethoxybenzoic acid methyl ester is identified as a novel pyrolysis product obtained from the cleavage of the pyran ring.
\end{abstract}

Electronic supplementary material The online version of this article (doi:10.1007/s10086-017-1633-4) contains supplementary material, which is available to authorized users.

Akiko Nakagawa-izumi

nakagawa-izumi.a.gm@u.tsukuba.ac.jp

1 Graduate School of Life and Environmental Sciences, University of Tsukuba, 1-1-1 Tennodai, Tsukuba, Ibaraki 305-8572, Japan

2 Research Center for Biomaterials, Indonesian Institute of Sciences (LIPI), Jl. Raya Bogor km. 46 Cibinong, Bogor 16911, Indonesia
Keywords Condensed tannin - Acacia crassicarpa $\cdot$ Bark waste $\cdot$ Pyrolysis-gas chromatography-mass spectrometry · Nuclear magnetic resonance

\section{Introduction}

Bark, a by-product of the pulp industry, is a renewable resource at pulp mills, in addition to wood wastes and black liquor [1]. Indonesia is the third largest manufacturer of pulp and paper in Asia, with 84 pulp and paper mills [2]; therefore, the country produces a significant amount of bark by-products. Bark contains a high concentration of tannin; as a result, interest in developing methods for utilizing tannin has recently increased. Studies have reported the utilization of tannin as a tanning agent [3], a protein precipitate [4, 5], an insecticide and a herbicide [6], a wood adhesive [7], and a wood preservative [8-10]. Tannin is divided into two major classes: condensed tannin and hydrolysable tannin. Condensed tannins consist of flavan3-ol units with $4 \rightarrow 6$ and $4 \rightarrow 8$ carbon linkages. The biological activity of tannin is closely related to structure, functional groups, and stereochemistry [11].

Acacia crassicarpa is a native species of Indonesia [12], which has been developed as a pulp and paper raw material owing to its better ability to grow in diverse environments as compared to Acacia mangium and Acacia auriculiformis [13]. Thus far, the increasing amount of bark waste produced by the pulp and paper industries is not offset by the utilization of its tannin content, partially because of the lack of detailed studies on the tannin from the bark of $A$. crassicarpa; only studies on the polyphenolic compounds from the knot and stem wood of A. crassicarpa have been reported thus far [14]. In these studies, melacacidin and isomelacacidin are identified as the main compounds, and 
low amounts of flavanone taxifolin, flavone quercetin, and flavanol catechin are also identified by gas chromatography-mass spectrometry (GC-MS).

Meanwhile, in New Zealand, South Africa, and other countries, A. mearnsii has long been planted, and its bark extracts have been utilized as a leather tanning agent. The structure of the condensed tannin contained in the bark of A. mearnsii (known as Morishima acacia in Japan) has been elucidated [11, 15] (Fig. 1).

This study aims to isolate the condensed tannins from $A$. crassicarpa and elucidate their chemical structures.

\section{Materials and methods}

\section{Bark sample of $A$. crassicarpa}

Bark samples were collected from 4- to 5-year-old $A$. crassicarpa trees grown in the Research and Development plantation area of PT Riau Andalan Pulp and Paper located in the Pelalawan area of Riau, Indonesia, in 2011. The samples were dried at room temperature for 2 weeks. Then, the air-dried bark was ground in a Wiley mill to obtain a powder with a mesh size of $40-80$.

\section{Extraction and fractionation of $A$. crassicarpa}

First, $40 \mathrm{~g}$ of bark powder (40-80 mesh size) was extracted using $300 \mathrm{~mL}$ of a $70 \%$ acetone aqueous solution at room temperature for $24 \mathrm{~h}$. Extraction was repeated four times. The resulting solvent was evaporated to obtain the $70 \%$ acetone extract, followed by dilution using $300 \mathrm{~mL}$ of aqueous water and extraction three times using $300 \mathrm{~mL}$ of ethyl acetate, affording the ethyl acetate extract (C-EA) and the water-soluble extract (C-WS).

C-EA was purified by column chromatography (length $=70 \mathrm{~cm}$ and $\varnothing=2.6 \mathrm{~cm}$ ) using a Sephadex LH20 (GE Healthcare Bio-Sciences, Sweden) with ethanol as

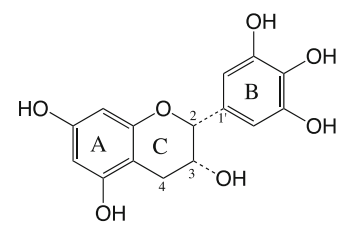

Epigallocatechin

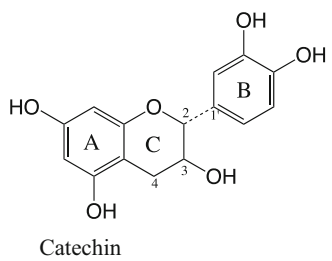

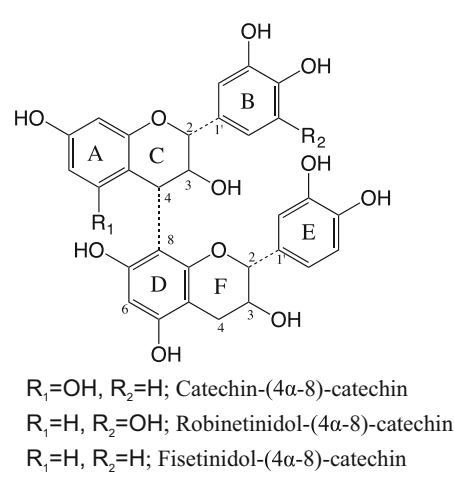

$\mathrm{R}_{1}=\mathrm{H}, \mathrm{R}_{2}=\mathrm{OH}$; Robinetinidol- $(4 \alpha-8)$-catech , Fisetinidol- $(4 a-8)-c a t e c h i n$

ig. 1 Examples of flavan-3-ol units of condensed tannin [11] the eluent, affording four fractions (C-EA1 to C-EA4, respectively). Each fraction was further purified by twodimensional thin-layer chromatography (2D TLC) using a mixture of ethyl acetate and $n$-hexane as the developing solution. Further separation of C-EA was performed using a $50 \%$ acetone aqueous solution to give a C-EA-AW fraction.

Using a similar procedure, C-WS was also purified by column chromatography (Sephadex LH-20) and further separated using a 50\% methanol aqueous solution and 50\% acetone, successively, to obtain a C-WS-AW fraction. Figure 2 shows the fractionation procedure.

\section{Pyrolysis-gas chromatography-mass spectrometry (Py-GC/MS)}

The samples (150-200 $\mu \mathrm{g})$ and the internal standard $n$ eicosane were wrapped in a $500{ }^{\circ} \mathrm{C}$ pyrofoil and pyrolyzed at $500{ }^{\circ} \mathrm{C}$ for $4 \mathrm{~s}$ using a JHP-5 pyrolyzer (Japan Analytical Industry, Japan), which was interfaced (interface temperature of $250^{\circ} \mathrm{C}$ ) with a GC-MS system (QP-5050, Shimadzu, Japan) equipped with an HP-1MS column $(30 \mathrm{~m} \times 0.25 \mathrm{~mm}$ i.d., film thickness $1.00 \mu \mathrm{m})$, with an electron impact of $70 \mathrm{eV}$ and $\mathrm{He}$ as the carrier gas. The injection port (temperature $280{ }^{\circ} \mathrm{C}$ ) was fit with a split liner (split ratio 50:1). The following temperature profile was used for GC analysis: hold for $1 \mathrm{~min}$ at $50{ }^{\circ} \mathrm{C}, 5 \mathrm{~min}$ at $50-280{ }^{\circ} \mathrm{C}\left(5{ }^{\circ} \mathrm{C} / \mathrm{min}\right)$, and $13 \mathrm{~min}$ at $280{ }^{\circ} \mathrm{C}$. The pyrolysis products were identified by the comparison of their retention times and mass spectra with those of the authentic samples and literature data. Catechin and epigallocatechin were purchased from Tokyo Chemical Industry (Tokyo, Japan) and used as model compounds for the tannin monomer.

Methylated Py-GC/MS was conducted by wrapping the condensed tannin samples in a $500{ }^{\circ} \mathrm{C}$ pyrofoil after the addition of $3 \mu \mathrm{L}$ of a $25 \%$ solution of tetramethylammonium hydroxide (TMAH, Tokyo Chemical Industry Co.,

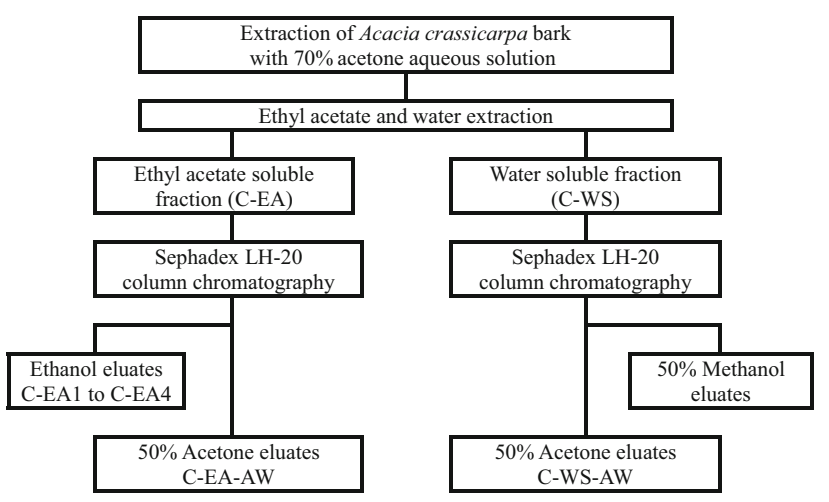

Fig. 2 Scheme of the extraction and fractionation of A. crassicarpa bark 
Table 1 Yields of acacia bark extracts containing condensed tannin

\begin{tabular}{lll}
\hline & $\begin{array}{l}\text { Acacia crassicarpa } \\
(\%)\end{array}$ & $\begin{array}{l}\text { Acacia mearnsii } \\
(\%)\end{array}$ \\
\hline $\begin{array}{l}70 \% \text { acetone aqueous } \\
\text { extracts }\end{array}$ & 7.0 & 34 \\
$\begin{array}{l}\text { Ethyl acetate-soluble } \\
\text { fraction }\end{array}$ & 0.8 & 12 \\
Water-soluble fraction & 6.2 & 22 \\
\hline
\end{tabular}

Ltd.) in methanol. The samples were analyzed using the same procedure as described above with conventional PyGC/MS. Gallic acid and 2,4,6-trimethoxybenzoic acid (Tokyo Chemical Industry Co., Ltd.) were used to identify the pyrolysis product of tannin, which exhibited an ion $\mathrm{m} /$ $z 226$.

\section{Pyrolysis-gas chromatography-milli mass spectrometry (Py-GC/Milli MS)}

The identification of the pyrolysis product with an $\mathrm{m} /$ $z$ value 226 was conducted using catechin, which was analyzed using a JMS-600H spectrometer (JEOL, Japan).

\section{Fast atomic bombardment mass spectroscopy (FAB-MS)}

FAB-MS spectra of the fractions (C-EA1 to C-EA4) from the condensed tannin samples were obtained using a JMS$600 \mathrm{H}$ spectrometer (JEOL, Japan) with Xe as the primary beam. FAB-MS measurements were conducted with sample solutions in a glycerol matrix with Ultramax 1621 as the standard.

\section{${ }^{1} \mathrm{H}$ and ${ }^{13} \mathrm{C}$ nuclear magnetic resonance (NMR) analyses}

The isolated dimer (C-EA1) from A. crassicarpa was analyzed using an AVANCE-500 NMR spectrometer at the Chemical Analysis Division, Research Facility Center for Science and Technology, University of Tsukuba, Japan using ethanol- $\mathrm{d}_{6}\left(\mathrm{CD}_{3} \mathrm{CD}_{2} \mathrm{OD}\right)$ as the solvent. The ${ }^{1} \mathrm{H}-$ NMR, ${ }^{13} \mathrm{C}-\mathrm{NMR}$, and two-dimensional NMR (2D NMR), i.e., heteronuclear multiple quantum coherence (HMQC), as well as distortionless enhancement by polarization transfer (DEPT 135), spectra were recorded at $500 \mathrm{~Hz}$.

Interpretation spectrum of ${ }^{1} \mathrm{H}-\mathrm{NMR}$ (TMS, tetramethylsilane) of C-EA1: $\delta 2.42$ [dd (double doublet), $J$ (coupling constant $)=16.1,8.0 \mathrm{~Hz}, \mathrm{H}-4 \mathrm{~F}(\mathrm{a})], 2.64$ [dd, $J=16.3,3.6 \mathrm{~Hz}$, H-3C(a)], 2.71 [dd, $J=16.3,4.7 \mathrm{~Hz}, \mathrm{H}-3 \mathrm{C}(\mathrm{b})], 2.74$ [dd, $J=16.1,5.4 \mathrm{~Hz}, \mathrm{H}-4 \mathrm{~F}(\mathrm{~b})], 3.86$ [ddd (double double doublet), $J=8.0,7.2,5.4 \mathrm{~Hz}, \mathrm{H}-3 \mathrm{~F}$ ], 4.05 [brdd (broad double doublet), $J=4.7,3.6 \mathrm{~Hz}, \mathrm{H}-2 \mathrm{C}$ ], 4.42 [d (doublet), $J=7.2 \mathrm{~Hz}, \mathrm{H}-2 \mathrm{~F}$ ], 4.63 [s (singlet), H-8aA], 5.80 [d, $J=2.3 \mathrm{~Hz}, \mathrm{H}-8 \mathrm{~A}$ ], 5.87 [s, H-6D], 5.89 [d, $J=2.3 \mathrm{~Hz}, \mathrm{H}-6 \mathrm{~A}$ ], 6.33 [s, H-2 ${ }^{\prime} \mathrm{B}$ and $\mathrm{H}-6^{\prime} \mathrm{B}$ ), 6.42 [bs (broad singlet), H-2 ${ }^{\prime} \mathrm{E}$ and $\left.\mathrm{H}-5^{\prime} \mathrm{E}\right]$. Fifteen protons were observed in the spectrum.

${ }^{13} \mathrm{C}-\mathrm{NMR}$ (TMS) of C-EA1: $\delta 28.0(\mathrm{C}-4 \mathrm{~F}), 28.8(\mathrm{C}-3 \mathrm{C})$, 67.2 (C-2C), 68.5 (C-3F), 79.5 (C-8aA), 82.5 (C-2F), 95.3-96.3 (C-6A, C-8A, C-6D), 99.6-100.4 (C-1'B, C-4C, $\left.\mathrm{C}-4 \mathrm{aD}, \mathrm{C}-6^{\prime} \mathrm{E}\right), 106.7\left(\mathrm{C}-2^{\prime} \mathrm{E}, \mathrm{C}-5^{\prime} \mathrm{E}\right), 107.0\left(\mathrm{C}-2^{\prime} \mathrm{B}\right.$ and C-6'B), 130.9-133.5 (C-4aA, C-4'B, C-8D, C-1'E), 146.1 (C-3'E, C-4 $\left.{ }^{\prime} \mathrm{E}\right), 146.3$ (C-3'B and C-5'B), 156.3-157.4 (C5A, C-7A, C-5D, C-7D, C-8aD).

The purified condensed tannin polymers from A. crassicarpa and $A$. mearnsii were analyzed using the AVANCE-500 NMR spectrometer (solvent: $\mathrm{CD}_{3} \mathrm{CD}_{2} \mathrm{OD}$ )
Fig. 3 Total ion chromatogram from methylated Py-GCMS of catechin and epigallocatechin a 1,2-Dimethoxybenzene; b 3,4dimethoxytoluene; c 1,2,3trimethoxybenzene; $\mathbf{d} 1,3,5$ trimethoxybenzene; e 2,4,6trimethoxytoluene; f 3,4,5trimethoxybenzaldehyde; g 3,4,5-trimethoxybenzoic acid methyl ester; $\mathbf{h}$ 2,4,6-trimethoxy benzoic acid methyl ester; and IS (internal standard): $n$ eicosane

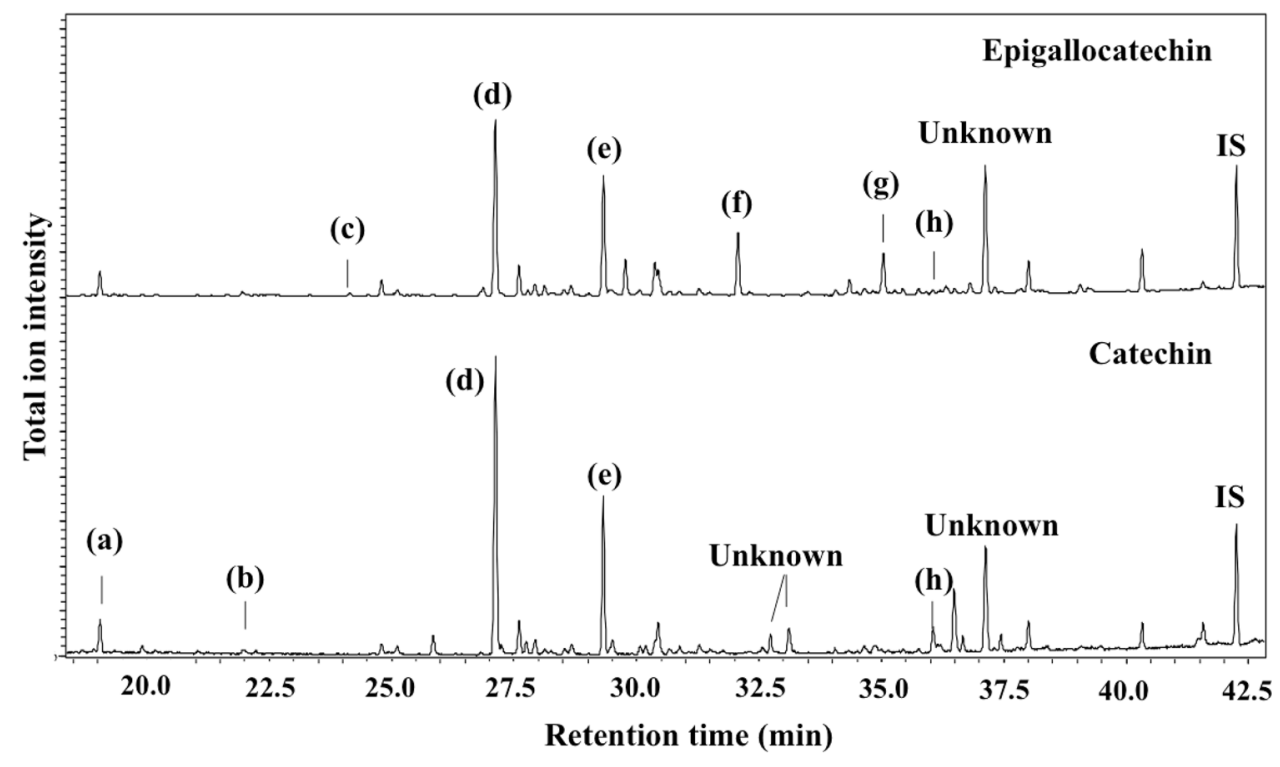


Fig. 4 Mass spectra of 2,4,6trimethoxy benzoic acid methyl ester and 3,4,5-trimethoxy benzoic acid methyl ester obtained by methylated Py-GC/ MS of 2,4,6-trimethoxy benzoic acid and gallic acid

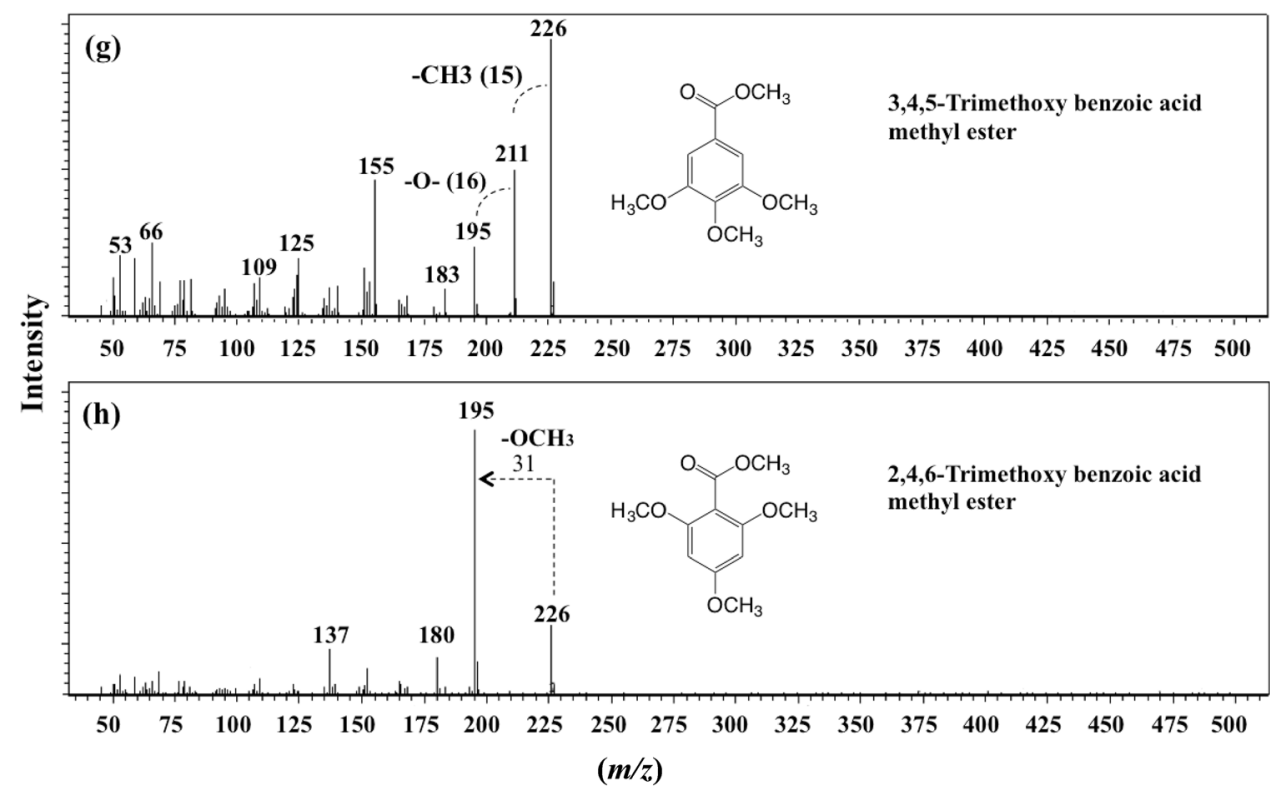

Fig. 5 Pyrogram of conventional Py-GCMS of C-EA1 and C-WS-AW from $A$ crassicarpa. 1 catechol; 2 resorcinol; 3 4-methylcatechol; 4 pyrogallol; 5 5-methyl pyrogallol; 6 phloroglucinol; and IS (internal standard): $n$ eicosane

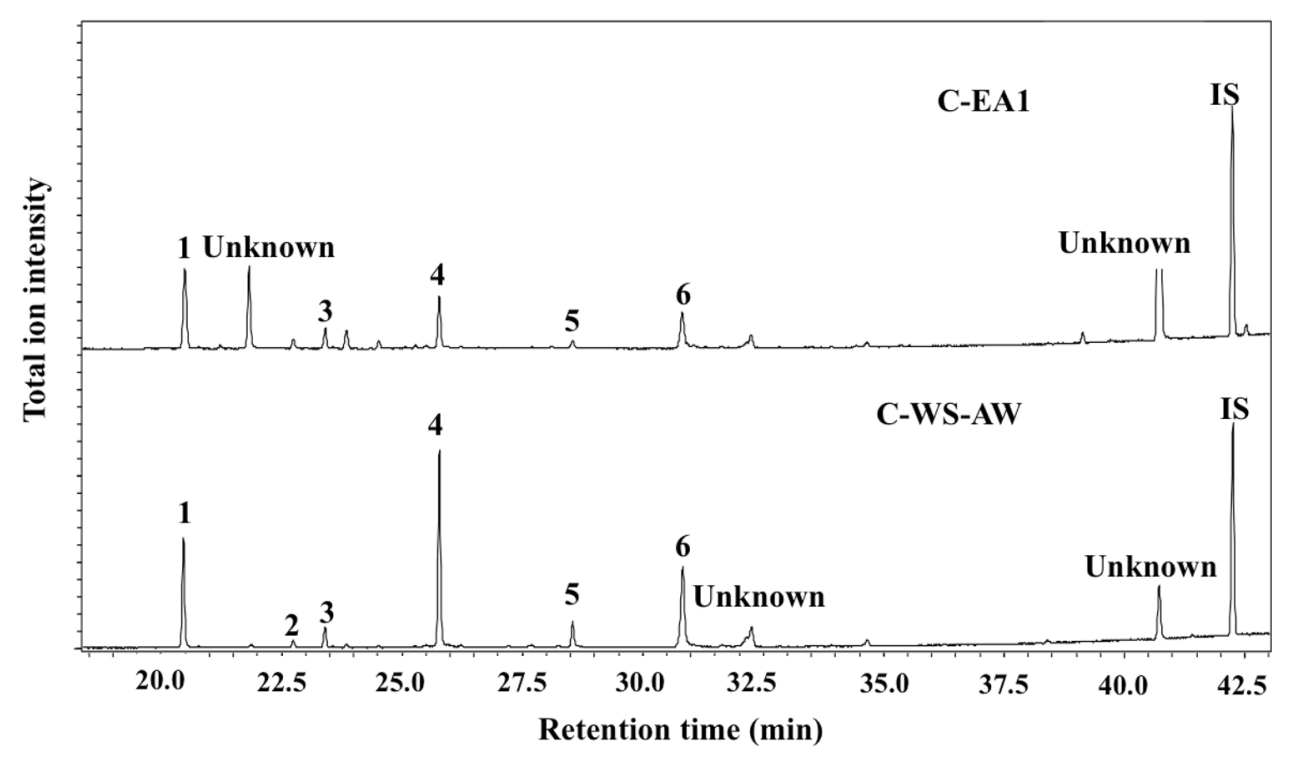

and a JEOL JNM-LA400 spectrometer (solvent: $\mathrm{CD}_{3-}$ $\mathrm{COCD}_{3}$ ), respectively.

\section{Results and discussion}

\section{Extraction of condensed tannin}

The yield of the extract obtained from A. crassicarpa (7.0\%) using a $70 \%$ acetone aqueous solution was one-fifth of that obtained from A. mearnsii (Table 1). This result is consistent with a previous study, which confirms that $A$. mearnsii is a good source of tannin [15]. In addition, the yield of the extract obtained from the bark of A. crassicarpa was less than that of other species, including A. mangium, A. auriculiformis, Rhizophora apiculata, and Larix leptolepis, with yields of 37.9, 28.6, 20.2, and $11.0 \%$, respectively [16]. The age of the tree and the location of sampling are known to affect the tannin yields; as compared to the outer or whole bark, the inner part of the bark has a higher amount of tannin because of the higher metabolite concentration [14].

\section{Structural elucidation of condensed tannin by Py- GC/MS}

\section{Py-GC/MS of catechin and epigallocatechin}

Catechin and epigallocatechin were used as monomer standards for flavanol. The main products from pyrolysis were catechol and 4-methylcatechol from the B-ring of 
Fig. 6 Pyrogram of methylated Py-GC/MS of C-EA1 and C-WA-AW from $A$.

crassicarpa. a 1,2dimethoxybenzene; b 3,4dimethoxytoluene; c 1,2,3trimethoxybenzene; $\mathbf{d}$ 1,3,5trimethoxybenzene; e 2,4,6trimethoxytoluene; f 3,4,5trimethoxybenzaldehyde; g 3,4,5-trimethoxybenzoic acid methyl ester; $\mathbf{h}$ 2,4,6-trimethoxy benzoic acid methyl ester; and IS (internal standard): $n$ eicosane

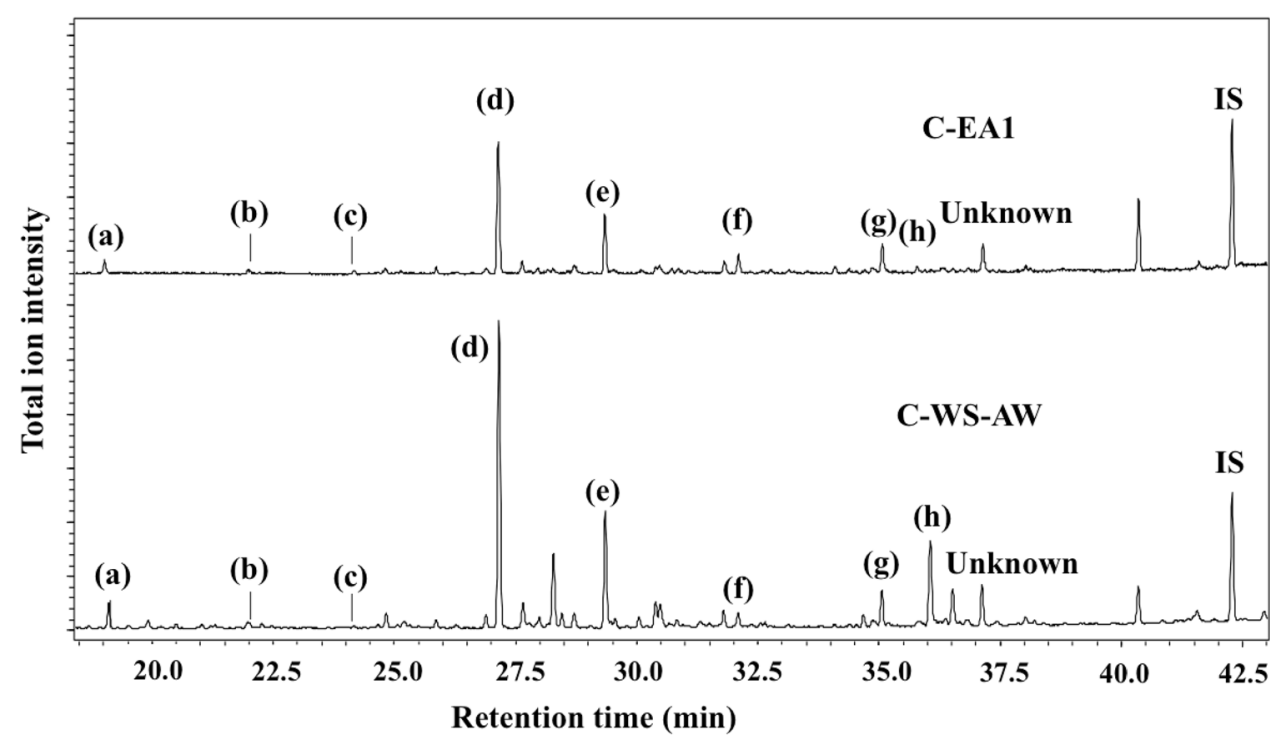

catechin and epicatechin (Fig. 1), while pyrogallol was the main product from epigallocatechin or gallocatechin. In this study, the intensity of the catechol peak was greater than that of 4-methylcatechol. This result confirmed that it is easier to cleave the $\mathrm{C1}^{\prime}-\mathrm{C} 2$ bond as compared to that of a pyran ring, which has been previously reported [11]. The presence of catechol or pyrogallol in the pyrogram is a very useful marker for the B-ring product, which can be used to identify the tannin structure. The yields of catechol and pyrogallol from catechin and gallocatechin have been reported to be 10.8 and $13.0 \mathrm{~mol} \%$, respectively, by conventional Py-GC [11].

In addition, a low-intensity peak corresponding to phloroglucinol was detected as a marker for the A-ring product. By conventional Py-GC/MS analysis, it is difficult to detect the A-ring products from pyrolysis as compared to the B-ring products because of their high polarity and instability under the conditions of the technique.

To overcome the polarity problem, methylated Py-GC/ MS can be used as an alternative method for analyzing the A-ring pyrolysis products from condensed tannin. In this method, the A-ring products are more easily detected than B-ring products. Figure 3 shows the methylated Py-GC/MS pyrogram of catechin and epigallocatechin obtained using TMAH as the methylating agent. Both the monomer standards, catechin and epigallocatechin, afforded the A-ring pyrolysis products, 1,3,5-trimethoxybenzene (d), and 2,4,6-trimethoxytoluene (e). Low amounts of the B-ring products, 1,2-dimethoxybenzene (a) and 3,4dimethoxytoluene (b), were also obtained from catechin, while 1,2,3-trimethoxybenzene (c), 3,4,5-trimethoxybenzaldehyde (f), which have been reported previously [17], and 3,4,5-trimethoxybenzoic acid methyl ester (g) were obtained from the B-ring of epigallocatechin.
In the methylated Py-GC/MS pyrogram of catechin and epigallocatechin, an unidentified mass ion $(\mathrm{m} / \mathrm{z})$ peak of 226 (h) was observed at a retention time of $36 \mathrm{~min}$. Based on the Py-GC/Milli MS data, this pyrolysis product (h) had a chemical formula of $\mathrm{C}_{11} \mathrm{H}_{14} \mathrm{O}_{5}$. However, the fragmentation trace and retention time of this peak did not match those of 3,4,5-trimethoxybenzoic acid methyl ester (g), which have been previously reported as a methylated Py-GC/MS product of wine tannin [18-20], and the ion fragmentation of 2,4,6-trimethoxybenzoic acid methyl ester (h) has not been reported. Hence, pure compounds 2,4,6-trimethoxybenzoic acid and gallic acid are subjected to methylated Py-GC/MS to identify the unknown fragmentation ion, and the results confirmed that the pyrolysis product (h) from catechin and epigallocatechin is 2,4,6-trimethoxybenzoic acid methyl ester (Fig. 4). It is formed from the cleavage of the pyran ring (C-ring) by the methylation of the tannin monomers, indicating that chain cleavage occurs at different locations in condensed tannins. 2,4,6-trimethoxybenzoic acid methyl ester was identified as a novel pyrolysis product. This property can be useful for determining the structures of unidentified condensed tannins.

\section{$P y-G C / M S$ of $C$-EAl and the tannin polymer fraction from A. crassicarpa}

Figure 5 shows the pyrogram of C-EA1 obtained by conventional Py-GC/MS. Catechol (1) and pyrogallol (4) were detected as the B-ring pyrolysis products, while phloroglucinol (6) was obtained as the A-ring product, and resorcinol was not observed. Figure 6 shows the methylated Py-GC/MS pyrogram of C-EA1 from A. crassicarpa. 1,3,5-Trimethoxybenzene (d), 2,4,6-trimethoxytoluene (e), and 2,4,6-trimethoxybenzoic acid methyl ester (h) were 


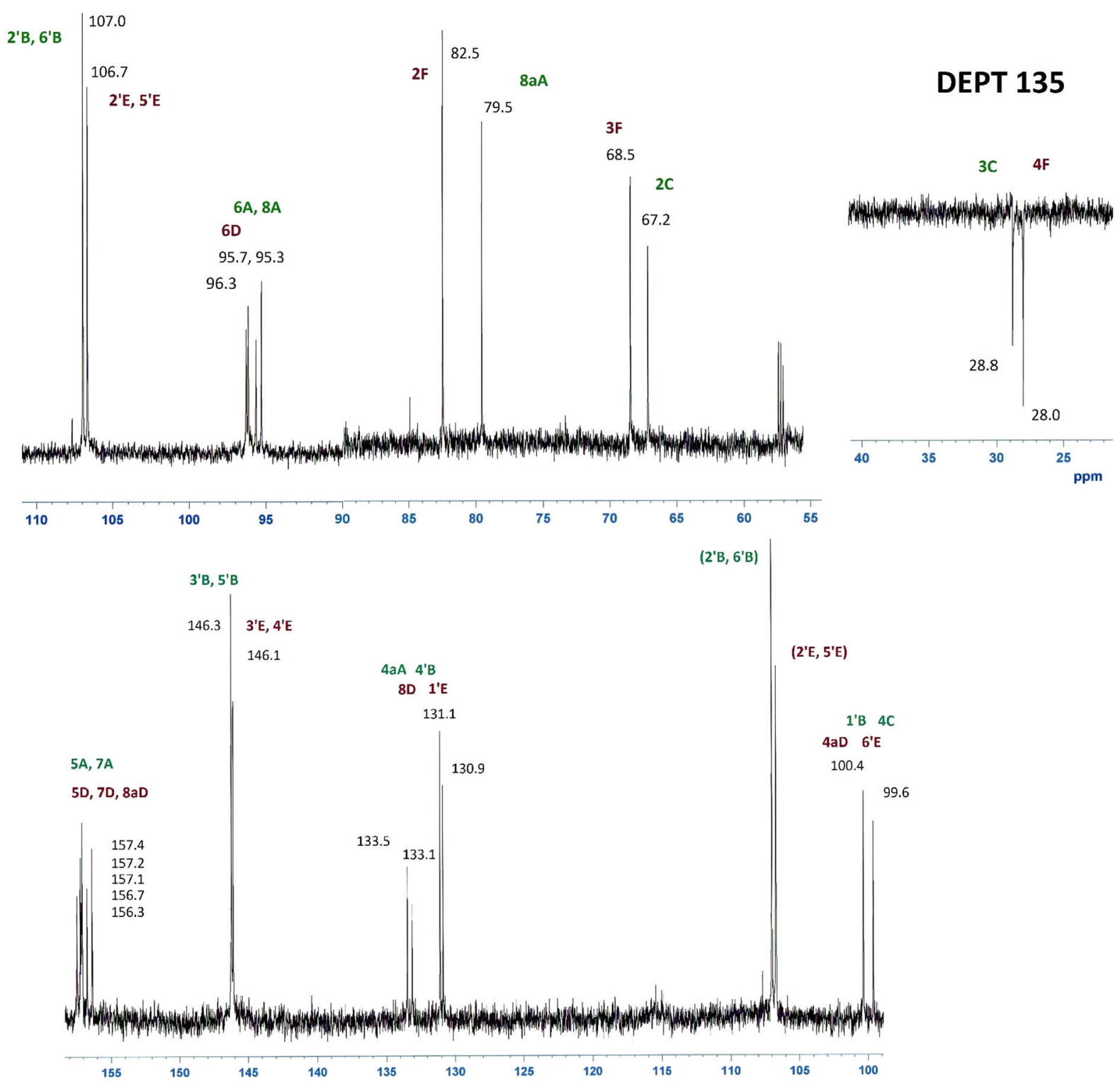

Fig. $7{ }^{13} \mathrm{C}$-NMR and DEPT 135 spectrum of the compound purified from C-EA1

detected as TMAH markers for the A-ring products. Meanwhile, the B-ring pyrolysis products-1,2,3trimethoxybenzene (c), 3,4,5-trimethoxybenzoic acid methyl ester (g), 1,2-dimethoxybenzene (a), and 3,4dimethoxytoluene (b) — were observed, with low intensities for the latter two compounds. Interestingly, an intense peak for 3,4,5-trimethoxybenzaldehyde (f) was detected as a result of the cleavage of $\mathrm{C}_{2}-\mathrm{C}_{3}$ bond on the C-ring. Based on these results, C-EA1 is a procyanidin or prodelphinidin, but it cannot be fisetinidol-(4-8)-catechin or robinetinidol(4-8)-catechin.

The purified tannin polymer fraction C-WS-AW contained catechol (1), 4-methylcatechol (3), pyrogallol (4), and 5-methylpyrogallol (6) as the B-ring pyrolysis products in the Py-GC/MS pyrogram. In addition, low amounts of phloroglucinol (6) and resorcinol (2) were observed from the A-ring (Fig. 5). In the methylated Py-GC/MS pyrogram, C-WS-AW contained 1,3,5-trimethoxybenzene (d), 2,4,6-trimethoxytoluene (e), and 2,4,6-trimethoxybenzoic acid methyl ester (h) as the A-ring products (Fig. 6). Together, these results clearly indicated that the condensed tannins of $A$. crassicarpa are predominantly composed of procyanidin and prodelphinidin.

\section{Characterization of dimers isolated from $A$. crassicarpa by FAB-MS and ${ }^{1} \mathrm{H}$ and ${ }^{13} \mathrm{C}-\mathrm{NMR}$ analyses}

C-EA1, C-EA2, C-EA3, and C-EA4 were collected from 1 to 64 fractions of the ethyl acetate-soluble fraction of 

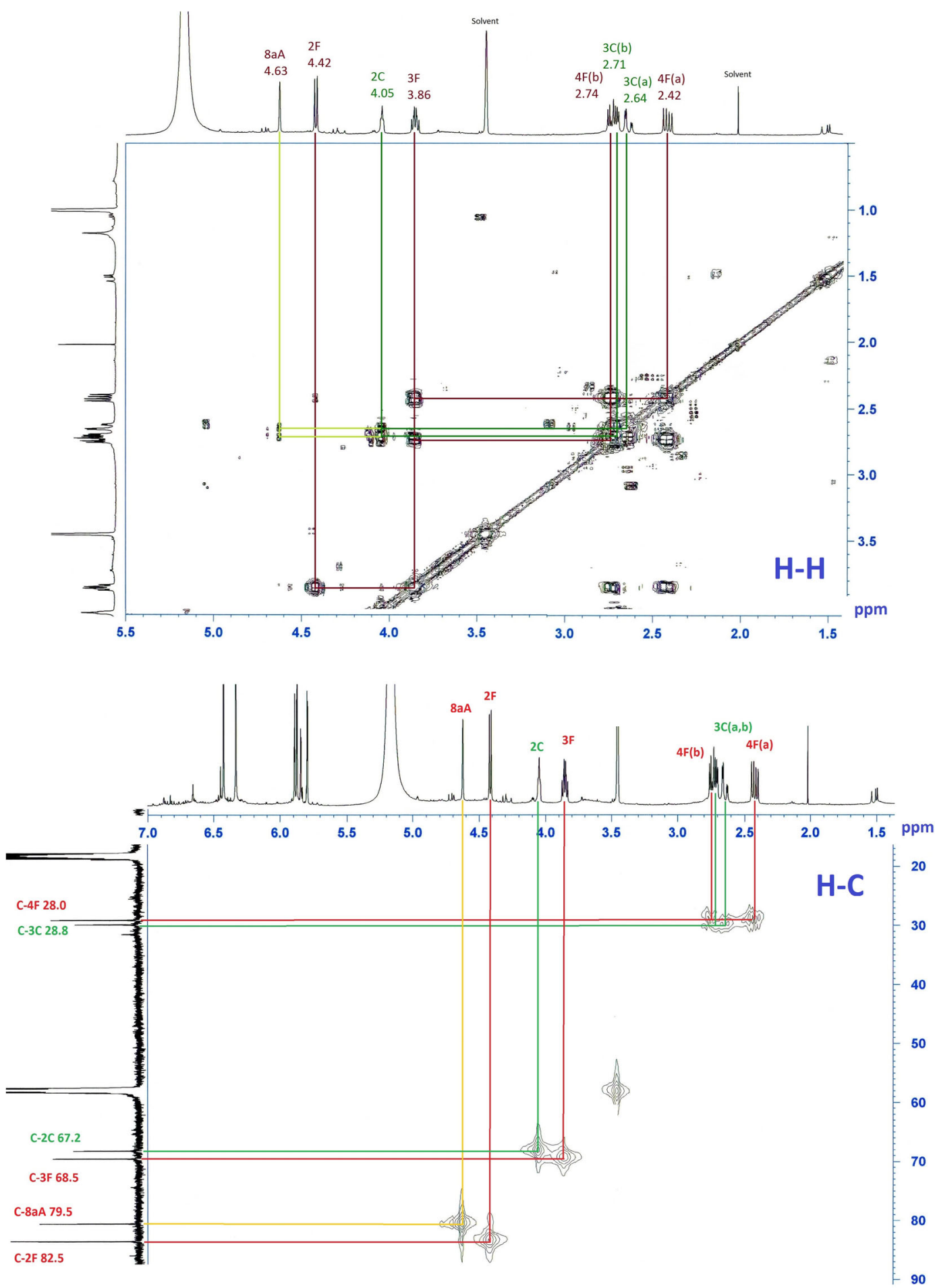

Fig. $8{ }^{1} \mathrm{H}$ and ${ }^{13} \mathrm{C}-\mathrm{NMR}$ HMQC spectrum of the compound purified from C-EA1

A. crassicarpa (C-EA), and a reddish brown amorphous powder $(92.7 \mathrm{mg})$ was obtained at $\mathrm{Rf}$ values: 0.77 ( $n$-hexane:ethyl acetate, $1: 1)$ and 0.40 (6\% acetic acid) of 2D-TLC as C-EA1 (1-16 fractions). The FABMS spectra of the compound C-EA1 $[\mathrm{M}+\mathrm{H}]^{+}$is 579 .
The ${ }^{1} \mathrm{H}-\mathrm{NMR}$ (TMS) and ${ }^{13} \mathrm{C}-\mathrm{NMR}$ (TMS) spectra of C-EA1 are described in the experimental section: 15 protons were observed.

The ${ }^{13} \mathrm{C}$-NMR of DEPT 135 spectrum of C-EA1 exhibited two methylene $\left(-\mathrm{CH}_{2}-\right)$ carbons with negative signals at 28.0 and $28.8 \mathrm{ppm}$, in addition to 11 methine (- 
Fig. 9 A possible structure of condensed tannin dimer from $A$. crassicarpa (MW: 578, $\mathrm{C}_{30} \mathrm{H}_{26} \mathrm{O}_{12}$ )<smiles>CC1(c2c(O)cc(O)cc2O)CC(c2cc(O)c(O)c(O)c2)Oc2c(O)c(O)cc(O)c21</smiles>

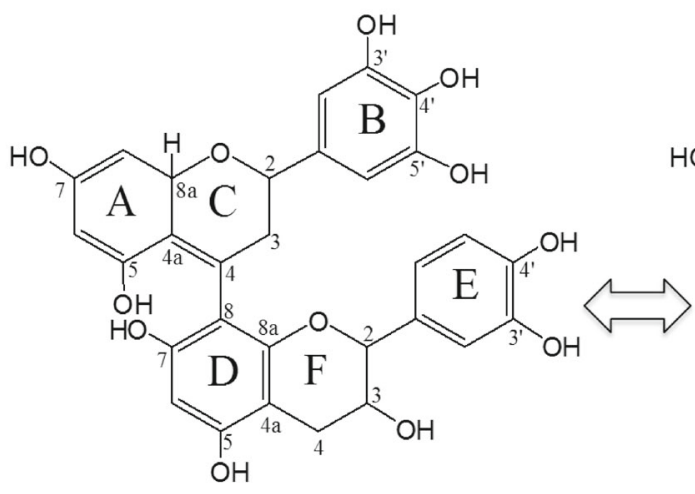

Isomerization

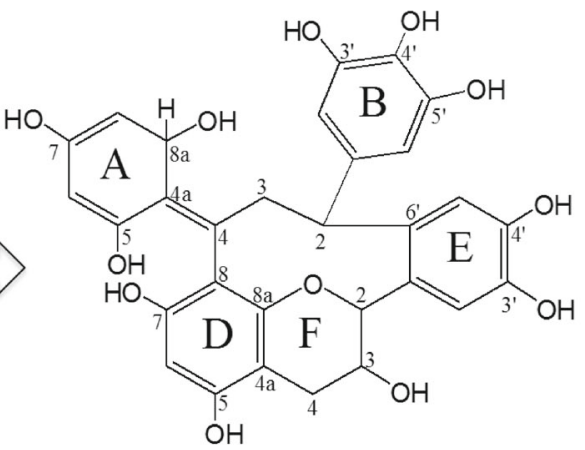

Condensation
$\mathrm{CH}-)$ carbons and 17 quaternary carbons $(-\mathrm{C}-)$, and $30{ }^{13} \mathrm{C}$ peaks were observed in the spectrum (Fig. 7). The ${ }^{13} \mathrm{C}$ NMR results indicated a clear difference between the chemical shift of C-3C $(\delta 28.8)$ and C-3F $(\delta$ 68.5). These assignments are supported by DEPT 135 data, which showed a negative signal for $\mathrm{C}-3 \mathrm{C}$, as methylene $\left(-\mathrm{CH}_{2}-\right)$. Furthermore, the analysis of the ${ }^{1} \mathrm{H}$ and ${ }^{13} \mathrm{C}$-NMR HMQC spectra was utilized to define the interaction between the protons and carbons in the compound (Fig. 8). The signal of ${ }^{13} \mathrm{C}$-NMR (HMQC) $(\delta 28.8)$ exhibited cross-peaks with $\mathrm{H}-3 \mathrm{C}$ (a) and (b) ( $\delta 2.64$ and 2.71), corresponding to a methylene carbon with no oxygen. This result confirmed the assignments of the F-ring (pyran ring) with the presence of hydroxyl group $(-\mathrm{OH})$.

Based on the interpretation by ${ }^{1} \mathrm{H}-\mathrm{NMR}$ and ${ }^{13} \mathrm{C}-\mathrm{NMR}$, isomerization and condensation were observed during the preparation of the C-EA1 sample. The dimer should change its structure according to the isomerization of a proton at C-4C to C-8aA and condensation of the benzyl cation (at $\mathrm{C}-2 \mathrm{C}$ ) of the B-ring to E-ring (at C- $6^{\prime} \mathrm{E}$ ).

Based on the above discussion, the dimer from the condensed tannin isolated from the bark of A. crassicarpa (C-EA1) is characterized as 2'-(3,4-dihydroxyphenyl)-2-

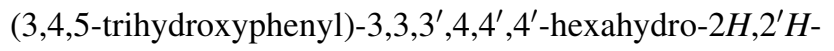
4,8-'bichromene- $3^{\prime}, 5,5^{\prime}, 7,7^{\prime}$-pentol (Fig. 9), or 5,7,3', $4^{\prime}, 5^{\prime}$ pentahydroxy-flavan-(4-8)-catechin. This is a novel dimer of condensed tannin, which contains a catechin and a flavan structure without an oxygen atom at the $3 \mathrm{C}$ of the pyran ring. The previously reported dimers fisetinidol-(48)-catechin and robinetinidol-(4-8)-catechin [21] were isolated from A. mearnsii extracts.

Unfortunately, 2D-NMR HMBC and NOESY data were not available because the compound was used for termite preservation tests, leaving insufficient amount of the compound for the analysis. Results from the analysis and termite tests will be separately reported in due course.

\section{Characterization of condensed tannin polymer by NMR analysis}

Polymer tannins are predominantly composed of repeating units of flavan-3-ols, which are linked via $\mathrm{C}_{4} \rightarrow \mathrm{C}_{6}$ or $\mathrm{C}_{4} \rightarrow \mathrm{C}_{8}$ bonds [22]. It is complicated to elucidate the structure of condensed tannin polymers because of their large molecular weights ranging from 2000 to 5000. This study approached the structural elucidation via the analysis 
of the flavanol units in polymer tannins, which consisted of pyrogallol- and catechol-type structures. In the Py-GC/MS pyrogram of C-WS-AW, the intensity of the pyrogallol peak was greater than that of catechol, indicating that the content of pyrogallol in polymer tannin is greater than that of catechol.

The C-WS-AW fraction was purified according to a previously reported method $[11,15,21]$. It may still contain impurities. For further studies, this fraction needs to be purified to a greater extent so as to obtain a clear ${ }^{13} \mathrm{C}-\mathrm{NMR}$ result.

The ${ }^{13} \mathrm{C}$-NMR spectrum was investigated for the condensed tannin polymers isolated from both $A$. mearnsii and A. crassicarpa. (Figs. ESM Appendix 1 and Appendix 2, respectively) The Py-GC/MS result, showing the presence of pyrogallol- and catechol-type structures, was supported by the presence of high-intensity chemical shifts in the ${ }^{13} \mathrm{C}$ NMR spectrum of WS-AW from A. mearnsii corresponding to $\mathrm{C}^{\prime}, \mathrm{C}^{\prime}$ (B-ring pyrogallol-type) and $\mathrm{C}^{\prime}, \mathrm{C}^{\prime}$ (Bring catechol-type) at $108 \mathrm{ppm}$ and $116 \mathrm{ppm}$, respectively $[23,24]$. In the case of C-WS-AW from A. crassicarpa, however, those peaks were slightly different, and the peaks were detected at $107.8 \mathrm{ppm}$ for the pyrogallol-type and $106.8 \mathrm{ppm}$ for the possible other type structures. The peak at $106 \mathrm{ppm}$ was possibly related to the condensed catechol type according to the results of the isolated dimer C-EA1.

\section{Conclusions}

The structure of condensed tannins from the bark wastes of A. crassicarpa were characterized for the first time. A novel dimer of flavan units specific to A. crassicarpa was isolated from the bark extracts. The new compound is a gallocatechin-catechin flavan dimer with no oxygen at the $3 \mathrm{C}$ of the pyran ring, which was characterized as $2^{\prime}-(3,4-$ dihydroxyphenyl)-2-(3,4,5-trihydroxyphenyl)-

$3,3,3^{\prime}, 4,4^{\prime}, 4^{\prime}$-hexahydro- $2 \mathrm{H}, 2^{\prime} \mathrm{H} 4,8$-'bichromene-

$3^{\prime}, 5,5^{\prime}, 7,7^{\prime}$-pentol, or $5,7,3^{\prime}, 4^{\prime}, 5^{\prime}$-pentahydroxy-flavan-(48)-catechin.

Acknowledgements The authors would like to thank Dr. Koh Hashida at the Forestry and Forest Products Research Institute (FFPRI), Japan, for providing valuable advices on NMR analysis of the isolated compound.

\section{References}

1. Consonni S, Katofsky RE, Larson ED (2009) A gasificationbased biorefinery for pulp and paper industry. Chem Eng Res Des 87:1293-1317

2. Rizaluddin AT, Salaghi A, Ohi H, Nakamata K (2016) Peroxymonosulfuric acid treatment as an alternative to ozone for totally chlorine-free and elementary chlorine-free bleaching of hardwoods prehydrolysis-kraft pulp. Jpn TAPPI J 70:724-733
3. Viviers PM, Botha JJ, Ferreira D, Roux DG, Saayman HM (1983) Synthesis of condensed tannins. Part 7. Angular [4,6;4,8]-prorobinetinidin triflavonoids from black wattle ('Mimosa') bark extract. J Chem Soc Perkins Trans 1:17-22

4. Hagerman AE, Butler LG (1981) The specificity of proanthocyanidin protein interaction. J Biol Chem 256:4494-4497

5. Kawamoto H, Nakatsubo F, Murakami K (1989) Synthesis of a condensed tannin model compound, 4-(2,4,6-trihydroxyphenyl)flavan-3,3',4',5,7-pentaol. J Wood Chem Technol 9:35-52

6. Scalbert A, Haslam E (1987) Polyphenols and chemical defence of the leaves of Quercus robur. Phytochemistry 26:3191-3195

7. Yazaki Y, Collins PJ (1994) Wood adhesives from Pinus radiata barks of some pine and spruce species. Holz als Roh-und Werkstoff 52:185-190

8. Laks PE, McKaig PA, Hemingway RW (1998) Flavonoid biocides: wood preservatives based on condensed tannins. Holzforschung 42:299-306

9. Ohmura W, Doi S, Aoyama M, Ohara S (1999) Components of steamed and non-steamed Japanese larch Larix leptolepis (Sieb et Zucc.) heartwood affecting the feeding behaviour of the subterranean termite Coptotermes formosanus Shiraki (Isoptera:Rhinotermitidae). Holzforschung 53:569-574

10. Ohmura W, Doi S, Aoyama M, Ohara S (2000) Antifeedant activity of flavonoids and related compounds against the subterranean termite Coptotermes formosanus Shiraki. J Wood Sci 46:149-153

11. Ohara S, Yasuta Y, Ohi H (2003) Structure elucidation of condensed tannins from barks by pyrolysis/gas chromatography. Holzforschung 57:145-149

12. Turnbull JW, Midgley SJ, Cossalter C (1998) Tropical acacia planted in Asia: an overview. In: Turnbull JW, Crompton HR, Pinyopusarerk K (eds) Recent developments in Acacia planting, ACIAR Proceedings No. 82. Australian Centre for International Agricultural Research, Canberra, Australia, pp 14-28

13. Awang K, Shukor NAA, Senin AL (1995) Two-year performance of Acacia crassicarpa Provenances at Serdang, Malaysia. Pertanika J Trop Agric Sci 18(3):177-181

14. Pietarinen SP, Willfor SM, Sjoholm RE, Holmbom BR (2005) Bioactive phenolic substances in important tree species. Part 3: knots and stemwood of Acacia crassicarpa and A. mangium. Holzforschung 59:94-101

15. Ohara S, Suzuki K, Ohira T (1994) Condensed tannins from Acacia mearnsii and their biological activities. Mokuzai Gakkaishi 40:1363-1374

16. Ohara S, Fujii T, Akitsuki K (2004) Formation of stable coating the wooden material surface by the application of tannin-charcoal suspensions. Bull FFPRI 3:1-6

17. Nierop KGJ, Preston CM, Kaal J (2005) Thermally assisted hydrolysis and methylation of purified tannin from plants. Anal Chem 77:5604-5614

18. Galletti GC, Modafferi V, Poiana M, Bocchini P (1995) Analytical pyrolysis and thermally assisted hydrolysis-methylation of wine tannin. J Agric Food Chem 43:1857-1863

19. Galletti G, Antonelli A (1993) The potential of pyrolysis(methylation)/gas chromatography/mass spectrometry in the analysis of wine polyphenolics. Rapid Commun Mass Spectrom 7:656-658

20. Galletti GC, Bocchini P (1995) Behaviour of catechin and ellagic acid subjected to thermally-assisted hydrolysis-methylation/gas chromatography/mass spectrometry. Rapid Commun Mass Spectrom 9:250-254

21. Hasumi M, Nakagawa-izumi A, Ohi H, Ohara S (2003) Structural elucidation of acacia tannin by pyrolysis-gas chromatography with on-line methylation. In: Proceeding of 12th International 
Symposium on Wood and Pulping Chemistry, Madison, WI, USA, vol II, pp 71-74

22. Schofield P, Mbugua DM, Pell AN (2001) Analysis of condensed tannins: a review. Anim Feed Sci Technol 91:21-40
23. Ohara S, Yanagi K (1995) Polyphenols from the bark of Salix rorida. Mokuzai Gakkaishi 41:406-413

24. Ohara S, Hujimori H (1996) Polyphenols from the bark of Salix pet-susu. Mokuzai Gakkaishi 42:618-623 